\title{
Descriptive Epidemiology of Factors Associated with HIV Infections Among Men and Transgender Women Who Have Sex with Men in South India
}

\author{
Souradet Y. Shaw, MSc, Robert Lorway, PhD, ${ }^{1}$ Parinita Bhattacharjee, MSc, \\ Sushena Reza-Paul, PhD, Elsabé du Plessis, MSc, Lyle McKinnon, PhD, ${ }^{3,4}$ \\ Laura H. Thompson, MSc, Shajy Isac, PhD, Banadakoppa M. Ramesh, PhD?, \\ Reynold Washington, MD, ${ }^{2,5}$ Stephen Moses, MD, ${ }^{1,6}$ and James F. Blanchard, MD, PhD ${ }^{1}$
}

\begin{abstract}
Purpose: Men and transgender women who have sex with men (MTWSM) continue to be an at-risk population for human immunodeficiency virus (HIV) infection in India. Identification of risk factors and determinants of HIV infection is urgently needed to inform prevention and intervention programming.

Methods: Data were collected from cross-sectional biological and behavioral surveys from four districts in Karnataka, India. Multivariable logistic regression models were constructed to examine factors related to HIV infection. Sociodemographic, sexual history, sex work history, condom practices, and substance use covariates were included in regression models.

Results: A total of 456 participants were included; HIV prevalence was $12.4 \%$, with the highest prevalence (26\%) among MTWSM from Bellary District. In bivariate analyses, district $(P=0.002)$, lack of a current regular female partner $(P=0.022)$, and reported consumption of an alcoholic drink in the last month $(P=0.004)$ were associated with HIV infection. In multivariable models, only alcohol use remained statistically significant (adjusted odds ratios: $2.6,95 \%$ confidence intervals: $1.2-5.8 ; P=0.02$ ).

Conclusion: The prevalence of HIV continues to be high among MTWSM, with the highest prevalence found in Bellary district.
\end{abstract}

Key words: alcohol use, HIV risk, India, men who have sex with men.

\section{Introduction}

T HE HUMAN IMMUNODEFICIENCY VIRUS (HIV) epidemic in India continues to be a global concern, with the heterosexual spread of HIV through female sex work, an important factor in earlier phases of the HIV epidemic in southern India. ${ }^{1}$ With a prevalence of $1.3 \%$ in prenatal clinics, Karnataka state in southern India was found to be one of six states with a high
HIV prevalence, ${ }^{1}$ triggering a considerable amount of investment in resources for prevention and intervention work. ${ }^{2}$

A challenge for prevention and intervention efforts is the tremendous amount of heterogeneity that exists in India. ${ }^{3}$ For example, within northern Karnataka, the presence of the Devadasi tradition (a form of sex work where young women are dedicated through marriage to gods or goddesses), ${ }^{4}$ geographic proximity to large urban centers in

\footnotetext{
${ }^{1}$ Department of Community Health Sciences, Centre for Global Public Health, University of Manitoba, Winnipeg, Manitoba, Canada.

${ }^{2}$ Karnataka Health Promotion Trust, Bangalore, India.

${ }^{3}$ Department of Medicine, University of Toronto, Toronto, Ontario, Canada.

${ }^{4}$ Department of Medical Microbiology, University of Nairobi, Nairobi, Kenya.

${ }^{5}$ St. John's Research Institute, Bangalore, India.

${ }^{6}$ Department of Medical Microbiology, University of Manitoba, Winnipeg, Manitoba, Canada.

(c) Souradet Y. Shaw et al. 2016; Published by Mary Ann Liebert, Inc. This Open Access article is distributed under the terms of the Creative Commons License (http://creativecommons.org/licenses/by/4.0), which permits unrestricted use, distribution, and reproduction in any medium, provided the original work is properly credited.
} 
Maharashtra state, and a largely rural population have conspired to produce substantially different drivers of the HIV epidemic compared to southern Karnataka ${ }^{5-8}$ In fact, a gradient in HIV prevalence from north to south, with a higher prevalence in the northern parts of Karnataka, is known to exist. ${ }^{6}$

Increasing emphasis has been placed on characterizing and responding to heterogeneity in the Indian HIV epidemic, and the different risk populations currently affected by $\mathrm{HIV},{ }^{9-11}$ such as among men and transgender women who have sex with men (MTWSM) ${ }^{10,12-15}$ MTWSM are recognized as a core group and are thus a priority for targeted interventions by the National AIDS Control Organization of India. ${ }^{16}$ Although recent studies have increased our understanding of MTWSM, ${ }^{9,11,17,18}$ there is still a paucity of data on the correlates of HIV infection among MTWSM in India. It is known that MTWSM in southern India have high rates of infection with HIV, ${ }^{10,13}$ as well as other sexually transmitted infections (STIs), ${ }^{11,13}$ relative to the general Indian population. For example, two studies of MTWSM in Karnataka state have reported HIV prevalence to be between $13 \%$ and $17 \%$ among MTWSM in their samples. ${ }^{10,11}$ In comparison, the HIV prevalence in the general male population in Karnataka state has been estimated at less than $1 \% .^{12,19}$ One survey of men living in Chennai slums found that the HIV prevalence was ninefold higher among MTWSM, compared to non-MTWSM individuals. ${ }^{20}$

Among MTWSM, HIV prevalence is known to vary by age, ${ }^{21,22}$ sexual identity, ${ }^{11,17,21,23}$ and location of residence, ${ }^{11}$ while the cruising location and level of literacy have been associated with HIV risk behaviors. ${ }^{22,24,25}$ A large body of literature exists on the relationship between sex work and HIV among MTWSM in India. ${ }^{23,26,27}$ Research has demonstrated that a substantial proportion of MTWSM are married, or have female sex partners ${ }^{11,17,21,22,25}$; at the same time, condom use has been demonstrated to be low among MTWSM. ${ }^{21,28}$ Age at first sex and composition of current sexual partners have been shown to be associated with HIV risk. ${ }^{11,22,29}$ Contributing to their risk for HIV, MTWSM in India remain highly stigmatized and marginalized in the Indian society ${ }^{26,30}$ and experience high rates of sexual violence. ${ }^{10,26,31,32}$ Finally, substance use, including alcohol use, has been shown to be elevated among MTWSM ${ }^{33}$ and has also been demonstrated to be associated with HIV. ${ }^{20,22}$

Thus, the higher prevalence of HIV and social and structural vulnerabilities (such as stigma, marginalization, and oppression) contribute to the creation of conditions that mirror the early spread of HIV among Indian female sex workers (FSWs). ${ }^{13,34}$ For example, MTWSM often live in poverty, are often involved in sex work, and are harassed by state institutions such as the police in India. ${ }^{26,35}$ At the same time, collectivization, community mobilization, and empowerment of FSWs are all thought to have played a vital role in curtailing the HIV epidemic among FSWs in Karnataka state. ${ }^{36,37}$ Although broadly less successful in MTWSM communities, due to the high stigmatization and illegality (in India) of same-sex relationships among men, Jha et al. note that peer-led education, community-led program planning and implementation, condom distribution and promotion, and integrated testing and treatment services were hallmarks of successful interventions among MTWSM communities. ${ }^{38}$ In terms of program planning, there are substantial gaps in knowledge regarding the correlates of HIV infection, and how, in turn, these correlates may affect prevention, screening, and treatment. ${ }^{38,39}$ For example, Thomas et al. note that the effect of alcohol and other substance use on risk for HIV has not been well studied in the Indian context. ${ }^{39}$ Therefore, studies describing the distribution of HIV among MTWSM and that examine the correlates of HIV infection are a priority for program planning. Using the most recent data available from a series of cross-sectional surveys of four districts in Karnataka State, southern India, this study sought to describe the prevalence of HIV among MTWSM and to examine factors related to HIV prevalence. The cross-sectional surveys were used to help evaluate the impact of the Bill \& Melinda Gates Foundation's Avahan program in India, which sought to curtail the spread of HIV in India. ${ }^{40,41}$

\section{Methods}

\section{Study design and sampling}

Institutional Review Boards at the University of Manitoba in Winnipeg, Canada, and St. John's Medical College and Hospital in Bangalore, India, approved the study and the verbal consent process. Interviews were conducted anonymously; because of the high level of stigmatization of MTWSM populations in India, verbal consent was obtained for all respondents in lieu of written consent, as MTWSM are reluctant to sign their names to documents. An independent witness signed each consent form, affirming that consent was correctly obtained.

Data were collected from the second round of a crosssectional survey (i.e., the Integrated Biological and Behavioural Assessment [IBBA]) of MTWSM populations in four districts in Karnataka State, southern India: Belgaum, Bellary, Mysore, and Shimoga. As part of a comprehensive monitoring and evaluation strategy, results from the IBBA were used to evaluate the impact of the Avahan program, which aimed to slow HIV transmission in India by bringing prevention efforts to scale among populations thought most at risk for HIV, including MTWSM. ${ }^{40,41}$ MTWSM in Belgaum $(n=198)$, Bellary $(n=71)$, Mysore $(n=100)$, and Shimoga $(n=87)$ were recruited in 2011 through multistage cluster sampling. ${ }^{17,42}$ Briefly, multistage cluster sampling is a sampling technique that takes advantage of natural, relatively homogenous clusters in a population and is thought to be highly efficient in the sampling of hard-to-reach populations. ${ }^{43} \mathrm{~A}$ sample size of 400 at the district level was thought adequate to detect an absolute difference of $15 \%$ or more from an assumed value of $50 \%$ in key behavioral characteristics between survey administrations, with 95\% confidence and 90\% power. ${ }^{41}$ The four districts in this analysis were treated as a single study. Program and mapping activities were directed at the most at-risk MTWSM and focused on those practicing receptive anal intercourse. These two concepts were operationalized by concentrating on MTWSM who gathered at cruising sites and other public spaces. ${ }^{17,42}$ Selection of solicitation sites occurred in the first stage of sampling, and selection of MTWSM in the second. Time-location cluster sampling was used to select specific clusters. Informed by previous mapping exercises, a total of 110 clusters with a minimum of five interviews in each cluster were targeted across the four districts. Within each cluster, MTWSM were randomly approached by field staff and asked to participate. Free transportation was then arranged to a private venue for MTWSM agreeing to participate. At the venue, MTWSM were explained IBBA procedures in detail and given the opportunity to ask questions; the 
voluntary nature of the survey was emphasized, especially the ability of the participant to withdraw participation at any point in the survey. Before field work and recruitment, a specific effort was made to inform community members of the scope, purpose, and the risks and benefits of the IBBA by field workers through community-based organizations. Participants were included in the study if they were 18 years or older and reported having had sex with a man at least once in their lifetime. Participants who were intoxicated or were otherwise unable to provide consent were excluded.

\section{Survey organization and methods}

MTWSM were interviewed individually by trained peer workers using a structured questionnaire administered in the local language. Biological data were gathered using blood and urine samples as described in previous studies. ${ }^{17,42}$ HIV serological testing was conducted using MicroELISA (J. Mitra and Company, India), and positive tests were confirmed using Genedia HIV 1/2 ELISA 3.0 (Green Cross Life Science Corporation, South Korea). When serum samples were not provided, dried blood spot testing was performed on finger prick blood using the same serological tests. When neither serum nor finger prick samples were provided, urine samples were tested for HIV by Calypte Biomedical Corporation (Berkeley, CA) and confirmed by Western blot. Because surveys and tests were conducted anonymously, results from HIV tests could not be linked back to individuals; however, syndromic treatment for bacterial sexually transmitted infections was provided on site, and vouchers were given to participants for free testing at community-based clinics.

\section{Measures}

In addition to the primary outcome (HIV status), respondents were compared on sociodemographic, sexual history, sex work-related, condom use, and substance use characteristics. Age group, literacy level (ability to read and write), marital status (ever married or never married), district of residence, and sexual identity were included as sociodemographic variables. Sexual identity among MTWSM is highly diverse; similar to other studies, ${ }^{10,17}$ MTWSM could self-identify as Kothis (those who primarily practice receptive anal sex and are feminine-acting males); Hijras (transgender people who often self-identify as female; many are castrated); Panthis (those who primarily practice insertive anal sex and are often clients of Kothis or Hijras); Double-deckers (DD) (those who practice both insertive/receptive anal sex), and others. MTWSM were grouped into the following identities: Kothis/Hijras; DD; and all others. ${ }^{10}$ Kothis and Hijras were grouped together for the purposes of statistical power. Finally, where respondent was recruited into the study (public garden/washroom, railway station/bus stop, or Hamam) was used as a proxy for where respondents cruised for sex with other MTWSM.

Sexual history included age at first sexual encounter with a man, whether first sex was forced (yes/no), and history of vaginal intercourse (yes/no). Binary variables for each of the following were created: whether the respondent currently had a regular female partner, a regular male partner, or no partner at all. Sex work-related questions included whether the respondent had ever engaged in sex work and binary variables created from questions asking whether respondents had ever paid for sex from FSWs and/or male sex workers. Condom use questions included asking whether respondents had ever used condoms, whether condoms were used at last anal sex with a male partner, whether respondents ever felt they could not use a condom in the past 6 months, and whether the decision to use condoms at last sex was entirely up to their partner. Finally, variables were created to capture the use of alcohol in the last month (ever vs. never), injection drug use, and use of other drugs. No respondent reported injection drug use, and only one reported use of other drugs; therefore, only alcohol use was included in further analyses.

\section{Statistical analysis}

Descriptive analyses included comparisons between HIVpositive and HIV-negative MTWSM based on sociodemographic, sexual history, sex work, condom use, and substance use characteristics.

\section{Multivariable analyses}

A hierarchical, stepwise approach was taken for parsimonious model building in multivariable logistic regression analyses. Factors of interest were grouped into five blocks: sociodemographic, sexual history, sex work, condom use, and substance use. A priori, age group, district of residence, and sexual identity were forced into models. As a consequence, the null model (Model 1) used for each comparison included age group, district, and sexual identity as covariates. In the first step, each block was entered separately into multivariable regression models in the following sequence: substance use, condom use, sex work, sexual history, and sociodemographic blocks. All blocks not associated with HIV status (adjusted for age group, sexual identity, and district) at $P<0.10$ were excluded from further analysis. In the second step, for each block remaining, covariates comprising the included block were entered into regression models individually. Covariates were kept if they were associated with the outcome at $P<0.10$ (Model 2). In the third step, all covariates that were excluded in the first and second steps of the model building process were entered individually into Model 2; any covariates significant at the $P<0.05$ level were then retained. This final step was repeated until no other covariates were associated with HIV status at $P<0.05$. Wald tests were used to assess statistical significance, and sampling weights were utilized in regression models to account for the complex sampling design, using survey methods in Stata 12 (College Station, TX). Multicollinearity was assessed using the variance inflation factor and tolerance statistics, corrected for the survey methods used. ${ }^{44}$

\section{Results}

A total of 456 respondents were included from an original study sample of 459. Two respondents were eliminated because they did not consent to HIV testing, and one other respondent was excluded due to missing responses for several variables. Table 1 includes a description of the sample, both for the total study group and by HIV status. The mean age of the sample was 32.1 years, with MTWSM identifying as DD composing $50 \%$ of the sample. At the bivariate level, HIV-positive respondents were more likely to be from Bellary $(P=0.002)$, less likely to report having a current regular female partner $(P=0.022)$, and more likely to report having at least one alcoholic drink in the last month $(P=0.004)$. HIV prevalence in the total sample was $12.4 \%$ (Table 2 ), with prevalence lowest 
Table 1. Sample Characteristics by HIV Status, MTWSM South India (Weighted \%, $N=456$ )

\begin{tabular}{lcccc}
\hline & $H I V-v e$ & HIV +ve & & \\
Variables & MTWSM & MTWSM & Total & \\
& $(\mathrm{n}=399)$ & $(\mathrm{n}=57)$ & $(\mathrm{n}=456)$ & $\mathrm{P}$ \\
\hline
\end{tabular}

Sociodemographic

Age group

$18-24$

25-29

30-39

$40+$

Sexual identity

Panthi/bisexual/ other

DD

Kothi/Hijra

District

Belgaum

Bellary

Shimoga

Mysore

Where recruited

Public garden/ toilet

Railway station/ bus-stop

Hamam

Can read and write

No

Yes

Ever married

No

Yes

Sexual history

Age at first sex

(with male)

$<15$

15-18

19-21

$>21$

First sex with male

forced

No

Yes

$17.0 \%$

$45.4 \%$

$23.7 \%$

$13.8 \%$

$15.6 \%$

$54.2 \%$

$15.6 \%$

$14.5 \%$

$16.9 \%$

$46.5 \%$

$22.7 \%$

$13.9 \%$

Have regular male partner

No

Yes

$46.1 \%$

$53.9 \%$

Have regular female partner

No $\quad 53.4 \%$

Yes $\quad 46.6 \%$

Has no regular partner

No $\quad 74.7 \%$

Yes $\quad 25.3 \%$

Has had vaginal sex

No

$45.7 \%$

$54.3 \%$

$59.9 \%$

$40.1 \%$

$60.4 \%$

$39.6 \%$

$50.5 \% \quad 46.6 \%$

$49.5 \% \quad 53.4 \%$

$69.7 \% \quad 55.5 \%$

$30.3 \% \quad 44.5 \%$

$64.3 \% \quad 73.4 \%$

$35.7 \% \quad 26.6 \%$

$43.3 \% \quad 45.4 \%$

$56.7 \% \quad 54.6 \%$

Sex work

Ever

No

Yes

$62.5 \%$

$52.6 \%$

$61.2 \%$

$47.4 \% \quad 38.8 \%$

Ever paid for sex

(MSW)

No

Yes

$90.5 \%$

$88.7 \%$

$90.3 \%$

$11.3 \% \quad 9.7 \%$

0.058
TABle 1. (CONTINUED)

\begin{tabular}{|c|c|c|c|c|}
\hline Variables & $\begin{array}{l}H I V-v e \\
M T W S M \\
(\mathrm{n}=399)\end{array}$ & $\begin{array}{c}H I V+v e \\
M T W S M \\
(\mathrm{n}=57)\end{array}$ & $\begin{array}{c}\text { Total } \\
(\mathrm{n}=456)\end{array}$ & $\mathrm{P}$ \\
\hline \multicolumn{5}{|c|}{$\begin{array}{l}\text { Ever paid for sex } \\
\text { (FSW) }\end{array}$} \\
\hline No & $98.0 \%$ & $98.8 \%$ & $98.1 \%$ & 0.620 \\
\hline Yes & $2.0 \%$ & $1.2 \%$ & $1.9 \%$ & \\
\hline \multicolumn{5}{|c|}{ Condom use } \\
\hline \multicolumn{5}{|c|}{$\begin{array}{l}\text { Could not use condom } \\
\text { (last } 6 \text { months) }\end{array}$} \\
\hline No & $88.9 \%$ & $83.8 \%$ & $88.3 \%$ & 0.396 \\
\hline Yes & $11.1 \%$ & $16.2 \%$ & $11.7 \%$ & \\
\hline \multicolumn{5}{|c|}{$\begin{array}{l}\text { Partner decides when } \\
\text { to use condom }\end{array}$} \\
\hline No & $92.9 \%$ & $91.0 \%$ & $92.6 \%$ & 0.621 \\
\hline Yes & $7.1 \%$ & $9.0 \%$ & $7.4 \%$ & \\
\hline \multicolumn{5}{|c|}{ Ever used condom } \\
\hline No & $2.5 \%$ & $0.0 \%$ & $2.2 \%$ & 0.263 \\
\hline Yes & $97.5 \%$ & $100.0 \%$ & $97.8 \%$ & \\
\hline \multicolumn{5}{|c|}{ Used condom at last sex } \\
\hline No & $1.0 \%$ & $0.0 \%$ & $0.8 \%$ & 0.446 \\
\hline Yes & $99.0 \%$ & $100.0 \%$ & $99.2 \%$ & \\
\hline \multicolumn{5}{|c|}{ Substance use } \\
\hline \multicolumn{5}{|c|}{ Alcohol frequency } \\
\hline Never & $38.7 \%$ & $18.9 \%$ & $36.3 \%$ & 0.004 \\
\hline Ever & $61.3 \%$ & $81.1 \%$ & $63.7 \%$ & \\
\hline
\end{tabular}

DD, double-deckers; FSW; female sex worker; HIV, human immunodeficiency virus; MSW, male sex worker; MTWSM, men and transgender women who have sex with men.

among 18-24-year olds (11.1\%) and highest among 25-29year olds (14.7\%). HIV prevalence was highest in Bellary $(26.3 \%)$ and lowest in Belgaum $(7.9 \%)$. HIV prevalence among Kothis/Hijras, Panthis/Bisexuals/others, and DDs was $15.3 \%, 13.7 \%$, and $9.9 \%$, respectively.

\section{Multivariable analysis}

Table 2 presents the results from multivariable analyses, with Models 1 and 2 showing the results from the hierarchical stepwise procedure. Model 2 was the final model chosen. In Table 2, Model 1 represents the base model used in the stepwise procedure. After the first step in the procedure 0.602 through which all five blocks were entered independently (from 5 to 1), only Block 5 (alcohol use, $P=0.046$ ) remained significantly associated with HIV status at the $P<0.10$ level.

0.022 In the next step, alcohol use within the last month $(P=0.046)$ was retained (Model 2). In this final model, after adjusting for all other variables in the model, only recruitment from Bellary (adjusted odds ratios [AOR]: 4.5 ; $95 \%$ confidence intervals $[\mathrm{CI}]: 2.2-9.4 ; P<0.001)$ and reporting having at least 0.742 one alcoholic drink (AOR: $2.6 ; 95 \%$ CI: $1.2-5.8 ; P=0.02$ ), relative to reporting never having an alcoholic drink in the last month, were significantly associated with HIV infection.

\subsection{Discussion}

Our results demonstrate that HIV infection continues to be a major issue among MTWSM in southern India, with an overall HIV prevalence of $12 \%$ in our sample. HIV prevalence reported in this study is slightly lower than the prevalence of $14 \%$ reported using data from Round 1 of the IBBA. ${ }^{10} \mathrm{HIV}$ 
Table 2. HIV Prevalence and AOR and 95\% CI From Logistic Regression Models Examining Characteristics Associated with HIV Status, MTWSM South India $(N=456)$

\begin{tabular}{|c|c|c|c|c|c|c|c|}
\hline & \multirow[b]{2}{*}{ HIV prevalence } & \multicolumn{3}{|c|}{ Model 1} & \multicolumn{3}{|c|}{ Model 2} \\
\hline & & $A O R$ & $95 \% C I$ & $P$ & $A O R$ & $95 \%$ CI & $\mathrm{P}$ \\
\hline \multicolumn{8}{|l|}{ Age group } \\
\hline $18-24$ & 11.1 & Ref & $5-\overline{-1} 25$ & $\overline{0} 20$ & Ref & $50-202$ & $\overline{5} 0$ \\
\hline $25-29$ & 14.7 & 1.57 & $0.57-4.35$ & 0.38 & 1.41 & $0.52-3.83$ & 0.50 \\
\hline $30-39$ & 11.8 & 1.45 & $0.60-3.47$ & 0.40 & 1.32 & $0.57-3.07$ & 0.51 \\
\hline $40+$ & 13.2 & 2.01 & $0.60-6.73$ & 0.25 & 2.02 & $0.61-6.67$ & 0.24 \\
\hline \multicolumn{8}{|l|}{ Sexual identity } \\
\hline Panthi/bisexual/other & 13.7 & Ref & - & - & Ref & - & - \\
\hline DD & 9.9 & 0.60 & $0.16-2.23$ & 0.43 & 0.64 & $0.16-2.51$ & 0.51 \\
\hline Kothi/Hijra & 15.3 & 0.87 & $0.23-3.32$ & 0.83 & 0.93 & $0.22-3.85$ & 0.92 \\
\hline \multicolumn{8}{|l|}{ District** } \\
\hline Belgaum & 7.9 & Ref & - & - & Ref & - & - \\
\hline Bellary & 26.3 & 5.15 & $2.37-11.21$ & 0.00 & 4.52 & $2.17-9.42$ & $<0.001$ \\
\hline Shimoga & 12.2 & 1.75 & $0.74-4.12$ & 0.20 & 1.78 & $0.74-4.30$ & 0.13 \\
\hline Mysore & 14.7 & 1.98 & $0.76-5.16$ & 0.16 & 1.32 & $0.48-3.62$ & 0.58 \\
\hline \multicolumn{8}{|l|}{ Where recruited } \\
\hline Public garden/toilet & 20.7 & I & I & I & l & I & I \\
\hline Railway station/bus-stop & 13.2 & l & I & I & I & l & I \\
\hline Hamam & 10.6 & l & 1 & 1 & l & 1 & I \\
\hline \multicolumn{8}{|l|}{ Can read and write } \\
\hline No & 11.8 & I & I & I & l & l & I \\
\hline Yes & 12.8 & l & l & l & l & l & l \\
\hline \multicolumn{8}{|l|}{ Ever married } \\
\hline No & 15.4 & I & I & I & l & I & I \\
\hline Yes & 9.3 & I & I & I & I & I & I \\
\hline \multicolumn{8}{|l|}{ Age at first MSM sex } \\
\hline$<15$ & 11.5 & l & I & I & I & I & ' \\
\hline $15-18$ & 14.5 & I & I & I & I & l & I \\
\hline $19-21$ & 8.6 & i & i & i & 1 & i & i \\
\hline$>21$ & 13.0 & l & l & l & l & l & 1 \\
\hline First MSM sex forced & & & & & & & \\
\hline No & 12.2 & l & I & l & I & l & I \\
\hline Yes & 12.5 & l & I & I & l & l & 1 \\
\hline Have regular male partner & & & & & & & \\
\hline No & 13.5 & 1 & I & l & I & I & I \\
\hline Yes & 11.5 & l & l & l & l & l & I \\
\hline Have regular female partner & & & & & & & \\
\hline No & 15.6 & I & I & I & I & I & I \\
\hline Yes & 8.5 & l & I & I & I & l & I \\
\hline Has no regular partner & & & & & & & \\
\hline No & 10.9 & I & I & I & I & I & I \\
\hline Yes & 16.7 & l & I & I & 1 & l & 1 \\
\hline Has had vaginal sex & & & & & & & \\
\hline No & 11.9 & I & I & I & 1 & I & I \\
\hline Yes & 12.9 & l & l & I & 1 & l & I \\
\hline Sex work-ever & & & & & & & \\
\hline No & 10.7 & l & I & I & I & l & I \\
\hline Yes & 15.2 & I & I & I & 1 & l & I \\
\hline Ever paid for sex (MSW) & & & & & & & \\
\hline No & 12.2 & I & I & I & 1 & I & I \\
\hline Yes & 14.5 & l & I & I & I & l & I \\
\hline Ever paid for sex (FSW) & & & & & & & \\
\hline No & 12.5 & I & I & I & l & I & I \\
\hline Yes & 7.8 & l & l & l & 1 & l & 1 \\
\hline Could not use condom $(6 \mathrm{~m}$ & & & & & & & \\
\hline No & 12.1 & I & I & I & l & I & I \\
\hline Yes & 17.6 & 1 & I & I & I & l & 1 \\
\hline Partner decides on condom & & & & & & & \\
\hline No & 12.5 & I & ' & I & 1 & I & ' \\
\hline Yes & 15.6 & 1 & I & I & l & l & I \\
\hline Ever used condom & & & & & & & \\
\hline No & 0.0 & I & I & I & 1 & I & 1 \\
\hline Yes & 12.7 & l & l & I & I & I & I \\
\hline Used condom at last sex & & & & & & & \\
\hline No & 0.0 & I & I & l & I & I & I \\
\hline Yes & 12.8 & I & 1 & I & 1 & I & 1 \\
\hline Alcohol frequency (last $1 \mathrm{~m}$ & & & & & & & \\
\hline Never & 6.5 & I & 1 & I & Ref & - & - \\
\hline Ever & 15.8 & I & I & I & 2.61 & $1.19-5.76$ & 0.02 \\
\hline
\end{tabular}

* Statistical significance at $P<0.05$ in Model 2.

**Statistical significance at $P<0.01$ in Model 2.

" /" are placeholders to signify exclusion from Models 1 and 2.

AOR, adjusted odds ratios; CI, confidence intervals. 
prevalence in our study is similar to those found among MTWSM in North America (15.4\%), Central/South America (14.9\%), and other parts of South and Southeast Asia (14.7\%), but lower than those reported from the Caribbean (25.4\%) and sub-Saharan Africa (17.7\%). ${ }^{45}$ Among MTWSM in India, HIV prevalence in our sample is higher than prevalence reported in the states of Maharashtra (11\%) and Tamil Nadu $(8 \%),{ }^{11,20}$ but lower than prevalence reported in Andhra Pradesh state $(21 \%) .{ }^{11}$ Compared to a recent study of MTWSM in 12 cities in India, the prevalence reported in our study was higher than the prevalence in 10 of 12 cities; only Hyderabad (12.7\%) and Madurai (13.1\%) reported higher HIV prevalence. In comparison to other priority populations in Karnataka state, studies have found HIV prevalences of $\sim 15 \%$ among FSWs, $5 \%$ among clients of FSWs ${ }^{46}$ and $0.8 \%$ in the general population. ${ }^{47}$ Consistent with other studies from India, our study found that HIV prevalence was highest among MTWSM who self-identified as Kothi or Hijra. ${ }^{11}$ Unlike other published studies, ${ }^{11}$ those who identified as DD had the lowest HIV prevalence, at $10 \%$. This may have been related to our inclusion of Panthis with the "Others" group, as Panthis were shown to have the lowest HIV prevalence in the study by Brahmam et al. ${ }^{11}$ In addition, the fact that more than $50 \%$ of our sample was composed of DD may have contributed to lowering HIV prevalence in this group through regression to the mean.

The observation that HIV prevalence was highest in Bellary, at $26.3 \%$, is consistent with Round 1 data from Karnataka state, with prevalence reported to be as high as $30 \%$ among MTWSM. ${ }^{48}$ Using the same data, Alary et al. reported HIV prevalence to be $16 \%$ among FSWs from Bellary, which was midway between the range of 10\%-34\% reported from five districts in Karnataka. ${ }^{48}$ Conversely, HIV prevalence among clients of FSWs was 6\%, which was one of the higher prevalences reported from Karnataka state. ${ }^{48}$ Bellary was identified as one of the high priority districts in Karnataka state by the United Nations Development Programme, ${ }^{48}$ given its high HIV prevalence in the general population, incidence of poverty, and more challenging socioeconomic conditions, including a high degree of wealth inequality. ${ }^{1,48}$ Moreover, and contributing to its vulnerability to $\mathrm{HIV},{ }^{49} \mathrm{Bel}-$ lary district is home to a large and prosperous mining industry and thus hosts a highly mobile migrant worker population. ${ }^{48}$

The impact of alcohol use on decision-making and risky sexual practices has been acknowledged, ${ }^{50}$ and further exploration of this issue among MTWSM in the Indian context has been argued for previously. ${ }^{39}$ However, with few exceptions, the impact of alcohol use on HIV risk among Indian MTWSM has rarely been studied. ${ }^{20,51}$ One Chennai-based study found that, at the univariate level, heavier alcohol use was associated with marriage to women and having unprotected anal and vaginal sex. ${ }^{51}$ These results highlight the role that subgroups of MTWSM may have in furthering HIV transmission to both the MTWSM and general populations. Mimiaga et al. observed that $28 \%$ of MTWSM reported using alcohol to the point of being intoxicated or buzzed weekly, and they recommend the provision of alcohol counseling as part of comprehensive prevention and intervention strategies for MTWSM.$^{51}$ Although our study did not include a formal measure of alcohol use or abuse (such as the CAGE measure), ${ }^{52}$ our results do confirm the need to include measures that enable a higher resolution of alcohol use in future studies. As others have suggested, discerning the extent to which alcohol is being used as a coping strategy to deal with issues of stigma and trauma would also be an important step to inform interventions focused on developing stronger adaptive coping strategies. ${ }^{53}$ Furthermore, on the treatment side, alcohol use has been associated with nonadherence to HIV medication, ${ }^{54,55}$ potentially affecting both the transmission of HIV and the health and well-being of MTWSM and other persons living with HIV/AIDS.

Our study had a number of strengths, including the integration of biological information with behavioral data. In addition, the focus of the IBBA was on MTWSM who were thought to be at highest risk of HIV infection/transmission. Finally, extensive premapping exercises and rigorous sampling methodology across several districts provided a robust and representative sample of MTWSM, to the greatest extent possible. Our study also had a number of limitations. First and foremost, alcohol use was measured broadly; future studies should incorporate more specific (and validated) measures of both frequency and abuse of alcohol. Second, although MTWSM were sampled from four different districts, substantial differences in sociocultural and political environments exist across different states in India; thus, inferences from our sample to other states and populations should only be undertaken with caution. Third, IBBA sampling methodology primarily relied on sampling from cruising sites and, therefore, our findings may not be generalizable to those MTWSM who do not frequent cruising sites. This sampling strategy was used, however, on the rationale that MTWSM who frequent cruising sites are at the highest risk of contracting HIV. It should also be noted that participants did receive a small gift as compensation for participating; this, as well as the fact that participants who were willing to participate in the survey may not be representative of MTWSM in Karnataka, further limits the generalizability of our findings. Fourth, the sexual identity categories for MTWSM were necessarily simplified and broad. Fifth, the possibility of recall bias exists as all behavioral questions were self-reported. Finally, data were of a cross-sectional nature and, thus, causality cannot be inferred from our study. The lack of statistical associations observed may indicate that a larger sample size may be needed in future studies. There was a large discrepancy in HIV prevalence, by district; however, samples were not sufficiently powered to perform district-level analyses.

\section{Conclusion}

In conclusion, using the latest available data on MTWSM from Karnataka state in India, we have found that HIV prevalence remains high and therefore remains a public health priority. Our results demonstrate an association between alcohol use and prevalent HIV infection, highlighting the need for further research to understand whether alcohol use may lead to further vulnerability.

\section{Acknowledgments}

The authors thank the participants, program staff, and field team for their time and dedication to this study. This research was funded by the Bill \& Melinda Gates Foundation. S.Y.S. is supported, in part, by doctoral awards from the Manitoba Health Research Council, David G. Fish Memorial Scholarship, the International Infectious Disease and Global Health Training Program, and the Canadian Institutes of Health Research. 


\section{Disclaimer}

The views expressed herein are those of the authors and do not necessarily reflect the official policy or position of the Bill \& Melinda Gates Foundation. The funders had no role in the study design, data collection and analysis, decision to publish, or preparation of the manuscript.

\section{Author Disclosure Statement}

The authors declare that no competing financial interests exist.

\section{References}

1. Moses S, Blanchard JF, Kang H, et al.: AIDS in South Asia: Understanding and Responding to a Heterogeneous Epidemic. Washington, DC: The International Bank for Reconstruction and Development/The World Bank, 2006.

2. Vassall A, Pickles M, Chandrashekar S, et al.: Costeffectiveness of HIV prevention for high-risk groups at scale: An economic evaluation of the Avahan programme in South India. Lancet Glob Health 2014;2:e531-e540.

3. Blanchard JF, Bhattacharjee P, Kumaran S, et al.: Concepts and strategies for scaling up focused prevention for sex workers in India. Sex Transm Infect 2008;84 Suppl 2:ii19-ii23.

4. O'Neil J, Orchard T, Swarankar RC, et al.: Dhandha, dharma and disease: Traditional sex work and HIV/AIDS in rural India. Soc Sci Med 2004;59:851-860.

5. Blanchard JF, O'Neil J, Ramesh BM, et al.: Understanding the social and cultural contexts of female sex workers in Karnataka, India: Implications for prevention of HIV infection. J Infect Dis 2005;191 Suppl 1:S139-S146.

6. Banandur P, Rajaram SP, Mahagaonkar SB, et al.: Heterogeneity of the HIV epidemic in the general population of Karnataka state, south India. BMC Public Health 2011;11 Suppl 6:S13.

7. Becker ML, Ramesh BM, Washington RG, et al.: Prevalence and determinants of HIV infection in South India: A heterogeneous, rural epidemic. AIDS 2007;21:739-747.

8. Banandur P, Ramanaik S, Manhart LE, et al.: Understanding out-migration among female sex workers in South India. Sex Transm Dis 2012;39:776-783.

9. Hernandez AL, Lindan CP, Mathur M, et al.: Sexual behavior among men who have sex with women, men, and hijras in Mumbai, India-multiple sex risks. AIDS Behav 2006; 10:S5-S16.

10. Shaw SY, Lorway RR, Deering KN, et al.: Factors associated with sexual violence against men who have sex with men and transgendered individuals in Karnataka, India. PLoS One 2012;7:e31705.

11. Brahmam GN, Kodavalla V, Rajkumar H, et al.: Sexual practices, HIV and sexually transmitted infections among self-identified men who have sex with men in four high HIV prevalence states of India. AIDS 2008;22 Suppl 5:S45-S57.

12. National AIDS Control Organization: HIV Sentinel Surveillance and HIV Estimation in India, 2007. A Technical Brief. In: Ministry of Health and Family Welfare (ed.), New Delhi, India, 2007.

13. Solomon SS, Srikrishnan AK, Sifakis F, et al.: The emerging HIV epidemic among men who have sex with men in Tamil Nadu, India: Geographic diffusion and bisexual concurrency. AIDS Behav 2010;15:1001-1010.

14. Verma RK, Collumbien M: Homosexual activity among rural Indian men: Implications for HIV interventions. AIDS 2004;18:1845-1847.
15. Dandona L, Sisodia P, Kumar SG, et al.: HIV prevention programmes for female sex workers in Andhra Pradesh, India: Outputs, cost and efficiency. BMC Public Health 2005;5:98.

16. National AIDS Control Organization: Targeted Interventions Under NACP III: Operational Guidelines Vol. 1 Core High Risk Groups. India: Government of India, 2007.

17. Phillips AE, Lowndes CM, Boily MC, et al.: Men who have sex with men and women in Bangalore, South India, and potential impact on the HIV epidemic. Sex Transm Infect 2010;86: 187-192.

18. Houston E, McKirnan DJ: Intimate partner abuse among gay and bisexual men: Risk correlates and health outcomes. J Urban Health 2007;84:681-690.

19. Munro HL, Pradeep BS, Jayachandran AA, et al.: Prevalence and determinants of HIV and sexually transmitted infections in a general population-based sample in Mysore district, Karnataka state, southern India. AIDS 2008;22 Suppl 5:S117-S125.

20. Go VF, Srikrishnan AK, Sivaram S, et al.: High HIV prevalence and risk behaviors in men who have sex with men in Chennai, India. J Acquir Immune Defic Syndr 2004;35:314-319.

21. Setia MS, Lindan C, Jerajani HR, et al.: Men who have sex with men and transgenders in Mumbai, India: An emerging risk group for STIs and HIV. Indian J Dermatol Venereol Leprol 2006;72:425-431.

22. Solomon SS, Mehta SH, Srikrishnan AK, et al.: High HIV prevalence and incidence among MSM across 12 cities in India. AIDS 2015;29:723-731.

23. Shinde S, Setia MS, Row-Kavi A, et al.: Male sex workers: Are we ignoring a risk group in Mumbai, India? Indian $\mathbf{J}$ Dermatol Venereol Leprol 2009;75:41-46.

24. Setia MS, Brassard P, Jerajani HR, et al.: Men who have sex with men in India: A systematic review of the literature. J LGBT Health Res 2008;4:51-70.

25. Kumta S, Lurie M, Weitzen S, et al.: Bisexuality, sexual risk taking, and HIV prevalence among men who have sex with men accessing voluntary counseling and testing services in Mumbai, India. J Acquir Immune Defic Syndr 2010;53: 227-233.

26. Chakrapani V, Newman PA, Shunmugam M, et al.: Structural violence against Kothi-identified men who have sex with men in Chennai, India: A qualitative investigation. AIDS Educ Prev 2007; 19:346-364.

27. Dandona L, Dandona R, Kumar GA, et al.: How much attention is needed towards men who sell sex to men for HIV prevention in India? BMC Public Health 2006;6:31.

28. Dandona L, Dandona R, Gutierrez JP, et al.: Sex behaviour of men who have sex with men and risk of HIV in Andhra Pradesh, India. AIDS 2005;19:611-619.

29. Gupta A, Mehta S, Godbole SV, et al.: Same-sex behaviour and high rates of HIV among men attending sexually transmitted infection clinics in Pune, India (1993-2002). J Acquir Immune Defic Syndr 2006;43:483-490.

30. Thompson LH, Khan S, du Plessis E, et al.: Beyond internalised stigma: Daily moralities and subjectivity among selfidentified kothis in Karnataka, South India. Cult Health Sex 2013;15:1237-1251.

31. Krug EG, Dahlberg LL, Mercy JA, et al.: World Report on Violence and Health. Geneva: World Health Organization, 2002.

32. Safren SA, Martin C, Menon S, et al.: A survey of MSM HIV prevention outreach workers in Chennai, India. AIDS Educ Prev 2006;18:323-332.

33. Phillips AE, Molitor J, Boily MC, et al.: Informal confidential voting interviewing in a sexual risk assessment 
of men who have sex with men (MSM) and transgenders (hijra) in Bangalore, India. Sex Transm Infect 2013;89: 245-250.

34. Steinbrook R: HIV in India—a complex epidemic. N Engl J Med 2007;356:1089-1093.

35. Lorway R, Reza-Paul S, Pasha A: On becoming a male sex worker in Mysore: Sexual subjectivity, "empowerment," and community-based HIV prevention research. Med Anthropol Q 2009;23:142-160.

36. Beattie TS, Mohan HL, Bhattacharjee P, et al.: Community mobilization and empowerment of female sex workers in Karnataka State, South India: Associations with HIV and sexually transmitted infection risk. Am J Public Health 2014;104:1516-1525.

37. Vassall A, Chandrashekar S, Pickles M, et al.: Community mobilisation and empowerment interventions as part of HIV prevention for female sex workers in Southern India: A cost-effectiveness analysis. PLoS One 2014;9:e110562.

38. Jha UM, Raj Y, Venkatesh S, et al.: HIV epidemic among men who have sex with men in India: National scenario of an unfinished agenda. HIV AIDS (Auckl) 2014;6:159-170.

39. Thomas B, Mimiaga MJ, Kumar S, et al.: HIV in Indian MSM: Reasons for a concentrated epidemic \& strategies for prevention. Indian J Med Res 2011;134:920-929.

40. Bill and Melinda Gates Foundation: Use It or Lose It: How Avahan Used Data to Shape Its HIV Prevention Efforts in India. New Delhi, India: Bill \& Melinda Gates Foundation, 2008.

41. Saidel T, Adhikary R, Mainkar M, et al.: Baseline integrated behavioural and biological assessment among most at-risk populations in six high-prevalence states of India: Design and implementation challenges. AIDS 2008;22 Suppl 5: S17-S34.

42. Phillips AE, Boily MC, Lowndes CM, et al.: Sexual identity and its contribution to MSM risk behavior in Bangaluru (Bangalore), India: The results of a two-stage cluster sampling survey. J LGBT Health Res 2008;4:111-126.

43. Verma R, Shekhar A, Khobragade S, et al.: Scale-up and coverage of Avahan: A large-scale HIV-prevention programme among female sex workers and men who have sex with men in four Indian states. Sex Transm Infect 2010;86 Suppl 1:i76-i82.

44. UCLA: Academic Technology Services Statistical Consulting Group. How can I check for collinearity in survey regression? 2010. Available at www.ats.ucla.edu/stat/stata/ faq/svycollin.htm. Accessed March 29, 2016.

45. Beyrer C, Baral SD, van Griensven F, et al.: Global epidemiology of HIV infection in men who have sex with men. Lancet 2012;380:367-377.
46. Shaw SY, Deering KN, Reza-Paul S, et al.: Prevalence of HIV and sexually transmitted infections among clients of female sex workers in Karnataka, India: A cross-sectional study. BMC Public Health 2011;11 Suppl 6:S4.

47. Pandey A, Sahu D, Bakkali T, et al.: Estimate of HIV prevalence and number of people living with HIV in India 2008 2009. BMJ Open 2012;2:pii:e000926.

48. Alary M, Jayachandran AA, Lowndes CM, et al.: Ecological analysis of the association between high-risk population parameters and HIV prevalence among pregnant women enrolled in sentinel surveillance in four Southern India states. Sex Transm Infect 2010;86 Suppl 1:i10-i16.

49. Piot P, Greener R, Russell S: Squaring the circle: AIDS, poverty, and human development. PLoS Med 2007;4:1571-1575.

50. Woolf SE, Maisto SA: Alcohol use and risk of HIV infection among men who have sex with men. AIDS Behav 2009; 13:757-782.

51. Mimiaga MJ, Thomas B, Mayer KH, et al.: Alcohol use and HIV sexual risk among MSM in Chennai, India. Int J STD AIDS 2011;22:121-125.

52. Ewing JA: Detecting alcoholism. The CAGE questionnaire. JAMA 1984;252:1905-1907.

53. Pence BW, Thielman NM, Whetten K, et al.: Coping strategies and patterns of alcohol and drug use among HIVinfected patients in the United States Southeast. AIDS Patient Care STDS 2008;22:869-877.

54. Harris J, Pillinger M, Fromstein D, et al.: Risk factors for medication non-adherence in an HIV infected population in the Dominican Republic. AIDS Behav 2011;15:1410-1415.

55. Venkatesh KK, Srikrishnan AK, Mayer KH, et al.: Predictors of nonadherence to highly active antiretroviral therapy among HIV-infected South Indians in clinical care: Implications for developing adherence interventions in resourcelimited settings. AIDS Patient Care STDS 2010;24:795-803.

Address correspondence to: Souradet Y. Shaw, MSc Department of Community Health Sciences Centre for Global Public Health University of Manitoba R070 Med Rehab Building 771 McDermot Avenue Winnipeg R3E 0T6 Manitoba Canada

E-mail: umshaw@myumanitoba.ca 